\title{
Gastric volvulus mimicking ST-segment elevation myocardial infarction
}

\author{
Jonathan Laurence Ciofani (D , 1,2 Kunwardeep Bhatia, ${ }^{1}$ Ravinay Bhindi, ${ }^{1,2}$ \\ Usaid K Allahwala ${ }^{1,2}$
}

'Department of Cardiology, Royal North Shore Hospital, St Leonards, New South Wales, Australia

${ }^{2}$ Faculty of Medicine and Health, The University of Sydney, Sydney, New South Wales, Australia

\section{Correspondence to}

Dr Jonathan Laurence Ciofani; jonathan.ciofani@sydney.edu.au

Accepted 19 August 2021
Check for updates

(c) BMJ Publishing Group Limited 2021. No commercial re-use. See rights and permissions. Published by BMJ.

To cite: Ciofani JL, Bhatia K, Bhindi $\mathrm{R}$, et al. BMJ Case Rep 2021;14:e245946. doi:10.1136/bcr-2021245946

\section{DESCRIPTION}

Mimics of ST-segment elevation myocardial infarction (STEMI) are common. We present the case of a STEMI mimic to highlight the importance of a broad differential diagnosis and multidisciplinary care.

A 58-year-old woman presented to our hospital with drowsiness, epigastric discomfort and nausea. Her medical history included hereditary spastic paraplegia requiring a permanent suprapubic catheter, gastro-oesophageal reflux disease, gastritis, chronic pain syndrome requiring an intrathecal baclofen pump and hypertension.

On examination, her Glasgow Coma Scale score was 11 (E3V3M5). She was haemodynamically stable without signs of respiratory distress. Her blood pressure was $152 / 107 \mathrm{mmHg}$; heart rate was 87 beats/min and regular; pulse oximetry saturation was $96 \%$ on room air; respiratory rate was 16 breaths/min; and she was afebrile.

The ECG on admission was notable for ST-segment elevation in the inferior leads (figure 1A), and the patient was emergently taken to the cardiac catheterisation laboratory. The angiogram demonstrated unobstructed coronary arteries, although a structure, presumed to be the stomach, was noted to be
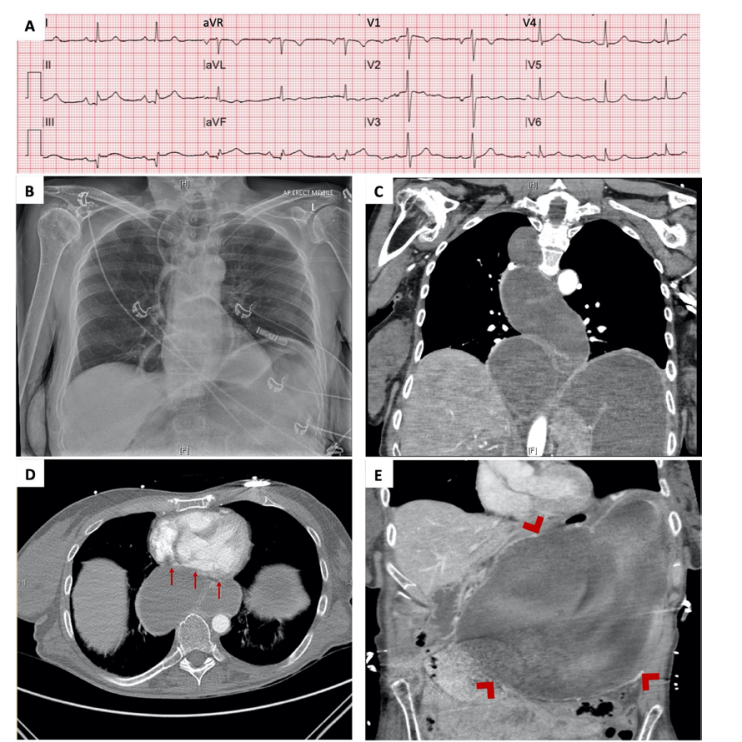

Figure 1 (A) ECG demonstrating inferior ST-segment elevation and PR-segment depression. (B-D) Chest X-ray (B), coronal (C) and axial (D) CT images demonstrating the hiatus hernia, dilated oesophagus and cardiac compression (arrows). (E) CT showing distended stomach (arrowheads) secondary to gastric volvulus.

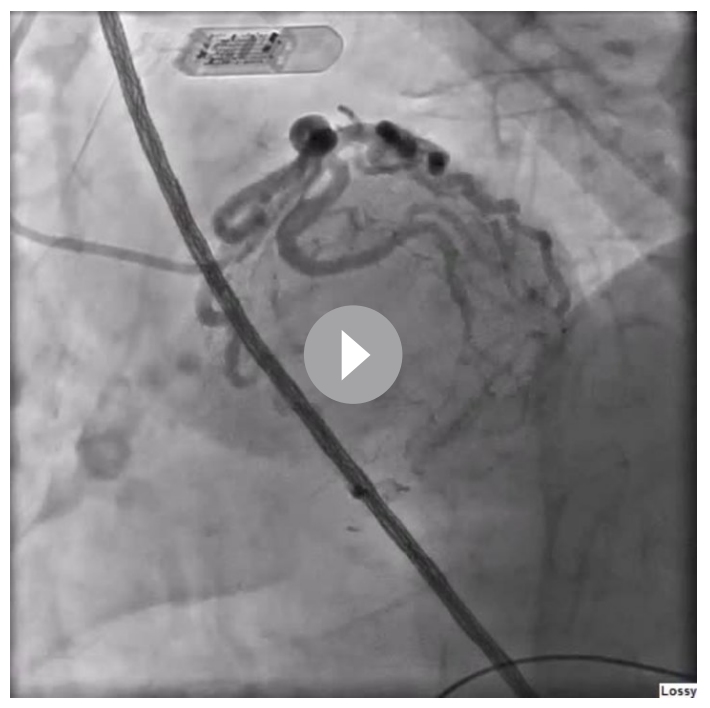

Video 1 Coronary angiogram demonstrating a structure oscillating against the inferior border of the heart (bottom left).
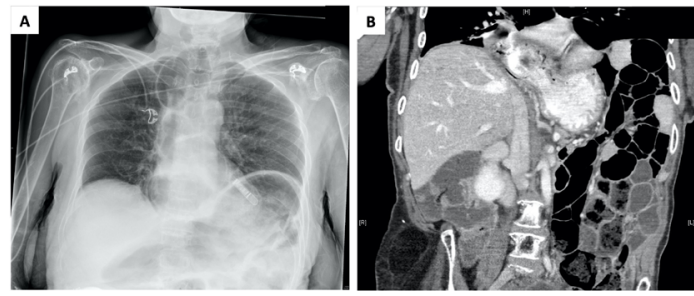

Figure 2 Follow-up chest X-ray (A) and CT (B) showed hiatus hernia and oesophageal tortuosity, but with resolution of the volvulus and maintenance of gastric decompression.

oscillating against the inferior heart border (video 1). A chest X-ray and CT of the chest demonstrated the presence of a hiatus hernia and dilated oesophagus with a gastric volvulus (figure 1B-E). Pathology results were unremarkable, notably with negative high-sensitivity serial troponins.

Following angiography, the ECG changes normalised after passage of a bowel motion. The patient was further managed with nasogastric tube decompression, and she elected for non-operative management. Repeat imaging at 3 months demonstrated ongoing hiatus hernia and oesophageal tortuosity, however there was resolution of the volvulus with maintenance of gastric decompression (figure 2). Repeat ECG at that time showed normal sinus rhythm without recurrence of ST-segment deviation. 
STEMI is a critical diagnosis with significant morbidity and mortality; however, mimics are common. The pathophysiological explanation of the initial ECG changes in this patient and whether the normalisation of ECG changes after the bowel motion was causally or coincidentally related are not entirely clear. Explanations suggested by previous reports include transient coronary occlusion through extrinsic compression or rotation of the heart in the thoracic cavity. ${ }^{1-3}$ However, the absence of troponin elevation and the presence of concurrent PR-segment depression in the inferior leads and PR-segment elevation in aVR suggest a direct effect of the stomach on the pericardium, causing pericardial irritation. Although this case is rare, it highlights the importance of a broad differential diagnosis

\section{Learning points}

- Mimics of ST-segment elevation myocardial infarction (STEMI) are common and may be emergencies in their own right.

- Gastric volvulus is a rare STEMI mimic which typically presents with epigastric pain.

- Patients with gastric volvulus may improve in the acute setting with nasogastric tube decompression alone. that extends beyond acute coronary syndrome when evaluating patients with an abnormal ECG.

Twitter Jonathan Laurence Ciofani @JonathanCiofani, Ravinay Bhindi @Ravinay and Usaid K Allahwala@UAllahwala

Acknowledgements We thank Dr Douglas Dunn (radiology) for support in image interpretation.

Contributors JLC: initial draft; JLC, KB, RB and UA: case identification, discussion of findings and manuscript revision.

Funding The authors have not declared a specific grant for this research from any funding agency in the public, commercial or not-for-profit sectors.

Competing interests None declared.

Patient consent for publication Obtained.

Provenance and peer review Not commissioned; externally peer reviewed.

\section{ORCID iD}

Jonathan Laurence Ciofani http://orcid.org/0000-0003-4476-6051

\section{REFERENCES}

1 Fang S-L, Deng M, Peng Y-N, et al. Gastric volvulus presenting as an acute coronary syndrome with long-lasting electrocardiographic changes. J Geriatr Cardiol 2019;16:309-12.

2 Farr C, Graver K, Curry RW, et al. Electrocardiographic changes with gastric volvulus. $N$ Engl J Med 1984;310:1747-8.

3 Pichon N. Gastric volvulus with electrocardiographic changes presenting as an acute coronary syndrome. Intensive Care Med 2016;42:1289-90.

Copyright 2021 BMJ Publishing Group. All rights reserved. For permission to reuse any of this content visit

https://www.bmj.com/company/products-services/rights-and-licensing/permissions/

BMJ Case Report Fellows may re-use this article for personal use and teaching without any further permission.

Become a Fellow of BMJ Case Reports today and you can:

- Submit as many cases as you like

- Enjoy fast sympathetic peer review and rapid publication of accepted articles

- Access all the published articles

- Re-use any of the published material for personal use and teaching without further permission

Customer Service

If you have any further queries about your subscription, please contact our customer services team on +44 (0) 2071111105 or via email at support@bmj.com.

Visit casereports.bmj.com for more articles like this and to become a Fellow 